\title{
Factors Affecting Voluntary HIV/AIDS Counseling and Testing Service Utilization Among Youth in Gondar City, Northwest Ethiopia
}

This article was published in the following Dove Press journal: HIVIAIDS - Research and Palliative Care

Asaye Tariku Alem '

Malede Mequanent Sisay ${(\mathbb{D})^{2}}^{2}$

Abiy Maru Alemayehu (D) ${ }^{3}$

'Amhara National Regional Health Bureau, Central Gondar Zone Health Department, Public Health Emergency Management Office, Gondar, Ethiopia; ${ }^{2}$ Department of Epidemiology and Biostatistics, Institute of Public Health, College of Medicine and Health Sciences University of Gondar, Gondar, Ethiopia; ${ }^{3}$ Department of Optometry, School of Medicine, College of Medicine and Health Sciences, University of Gondar, Gondar, Ethiopia
Correspondence: Malede Mequanent Sisay

Tel +25I9l85206II

Email maledecsa@gmail.com
Background: Voluntary counseling and testing (VCT) is a vital response to human immunodeficiency virus (HIV) infection among adolescents in sub-Saharan Africa. Determining the status of VCT services is important to link HIV care and antiretroviral therapy.

Methods: An institutional cross-sectional study design was conducted among 841 young students at Gondar College of Teachers' Education. A self-administered questionnaire was used to gather the data. Descriptive statistics were performed. Bivariate and multivariable binary logistic regressions were used to identify factors associated with the use of VCTs. The adjusted odds ratio (AOR) with $95 \%$ confidence was used to report statistical significance. Results: The majority (71\%) were aware of VCT services. More than one-third $(37.8 \%, 95 \%$ CI: 34.6-41.2) participants had used VCT services. Having peer groups used VCT $(\mathrm{AOR}=2.04,95 \% \mathrm{CI}: 1.31-3.20)$, having partner $(\mathrm{AOR}:=1.6,95 \% \mathrm{CI}: 1.04-2.45)$, desiring to have VCT in the future (AOR=3.58, 95\% CI: 1.98-6.50), being aware of VCT (AOR= 1.98, 95\% CI: 1.20-3.34), knew infected/dead individuals with HIV/AIDS (AOR=1.67, 95\% CI: $1.07-2.61)$, know test sites $(\mathrm{AOR}=2.01,95 \% \mathrm{CI}: 1.29-3.13)$ were positively associated, whereas being married (AOR $=0.36,95 \% \mathrm{CI}: 0.20-0.63$ ) and fear of confidentiality ( $\mathrm{AOR}=0.23$, 95\% CI: $0.10-0.52$ ) were major barriers to use.

Conclusion: Low use of VCTs, which was far away from the 90:90:90 WHO goal, has been noted. The use of VCT services was associated with having peer groups that used VCT, having a partner, wanting to have VCT in the future, knowing the infected/dead individual with HIV/AIDS, fear of confidentiality of results, knowing the test sites, and having awareness of VCT. Efforts are needed to strengthen the health system that also needs to pay attention to education about HIV and VCT.

Keywords: youth, VCT utilization, Ethiopia, HIV

\section{Background}

Acquired immunodeficiency syndrome (AIDS) is still a big health concern globally. Out of 36.9 million people living with HIV/AIDS, 1.8 million newly infected, and 940,000 AIDS deaths were reported in 2017. Among 25.7 million cases the HIVpositive population in the world, $69 \%$ of them are in sub-Saharan Africa. ${ }^{1}$ Despite a national prevalence of $1.15 \%$, Ethiopia has one of the highest HIV rates, covering nearly 718,550 cases and 9,294 deaths in $2018 .^{2-7}$

The 90-90-90 World Health Organization (WHO) targets for monitoring and treating the HIV epidemic is accepted by most nations. Nevertheless, only $34 \%$ of the people living with HIV knew their status worldwide in 2017. On the other 
hand, about 9.4 million people living with HIV do not know their status. ${ }^{8}$ The global pandemic affects primarily young children and young adults, especially SubSaharan Africa, which accounts for $25 \%$ of new HIV infections among young girls and young women. For example, 610,000 young people between 15 and 24 years old were present in 2016 alone. ${ }^{6,9-12}$ The latest figures indicate that only $10 \%$ to $15 \%$ of adolescents and $24 \%$ to $39 \%$ of young people were tested for HIV in subSaharan Africa. ${ }^{6,7,11}$ Research indicates that the core dangers of HIV infection are negative gender stereotypes and disparities, insufficient access to education, insecurity, and abuse. ${ }^{7,13}$ In many low-resource settings, voluntary counseling and testing (VCT) have been implemented. $^{14,15}$ The role of VCT as the gateway for the global response to the HIV/AIDS epidemic is the expansion of antiretroviral therapy, even though its use was small. $^{16}$

Few findings from Ethiopian research have shown that the use of voluntary counsels and test services is low and the level of use varies across different population segments. Just $18 \%$ of ages $15-24$ were checked and $67 \%$ know their status. ${ }^{11,17,18}$ The relationships between HIV testing and various social-demographic, behavioral, psychosocial, and systemic factors have been recorded by the study. However, VCT use remains inadequate in Ethiopia. This study determined how young people at Gondar Teacher's College in Northwest Ethiopia use VCT services and related factors.

\section{Methods and Materials Setting, Study Design and Population}

The institution-based cross-sectional study design was conducted at the Gondar College of Teachers' Education, Ethiopia, in May 2018. There were 5226 regular college students. In the city, two NGO clinics are providing reproductive health services to adolescents and youth groups. Eight government health centers and one referral hospital give VCT services. The study population included all regular students attending the Gondar College of Teachers' Education.

\section{Sample Size Determination and Sampling Technique}

A single proportion method was used to calculate the sample size, from a previous study (10), the proportion of VCT use was $46.1 \%,(p=0.461)$ and $q$ was 0.539 .
Taking the maximum allowable error $\mathrm{d}=5 \%$, the sample size was calculated as follows.

$$
\begin{gathered}
n=\frac{Z_{\frac{\alpha}{2}}^{2}}{d^{2}} * p(1-P)=\frac{1.96^{2} * 0461 * 0.539}{0.05^{2}}=382 \\
\text { where } Z_{\frac{\alpha}{2}}=1.96
\end{gathered}
$$

By considering 2 design effects and a $10 \%$ non-response rate the final sample size was 841 .

First, we selected 4 out of 12 departments using the lottery method. Then, participants were selected using a systematic random sample using the College Registrar list as a sampling frame. Finally, samples were allocated proportionally to selected departments and year of study.

\section{Data Collection Procedures}

A standardized, self-administered questionnaire was used to collect data. It was first written in English and then translated into Amharic, then returned to English to ensure consistency. In the Tseda Health Science School, the questionnaire was tested to retain consistency. Supervisors and facilitators of data collection were trained on the data collection process.

\section{Operational Definition \\ Voluntary Counseling and Testing}

A HIV test means where the test person gives informed consent and is advised and tested voluntarily and freely. $^{16,19}$

\section{Voluntary Counseling and Testing Utilization}

During the last 12 months, it is assessed if participants in the study voluntarily use the HIV testing service. ${ }^{19,20}$

\section{Knowledgeable About HIVIAIDS/VCT}

Respondents with average and above ratings of how HIV/ AIDS and VCT are transmitted, prevented, and correctly conceived. $^{16,19}$

\section{Data Analysis}

The data were entered into EPI-INFO version 7 and exported to SPSS version 20.0 for analysis. For most variables, descriptive statistics were used. To identify essential VCT predictors, bivariate, and multivariable binary logistics regression were used. The model fitness for the logistic regression was tested with Hosmer and Lemeshow tests. The Adjusted odds ratio with a 95\% confidence level is reported. In this study, an association was considered at a P-value of $<0.05$. 


\section{Results}

\section{Socio-Demographic Characteristics of Respondents}

Out of a total of 827 participants, 396 (47.9\%) were male with a mean age of $21( \pm 2.2 \mathrm{SD})$ years. The majority $(82.8 \%)$ were single participants. Four hundred and twenty $(50.8 \%)$ of them had boy/girlfriends (Table 1$)$.

\section{VCT Utilization and HIV Service-Related Characteristics}

A total of 313 (37.8\%; 95\% CI: 34.6-41.2) participants used VCT in the last 12 months. Among these, 152 (48.6\%) were male, and $67.5 \%$ were in the 20-24 age group. VCT was used by the majority of young people in the second year of study $116(42.8 \%)$, followed by third year $127(38.4 \%)$ and 1st year $70(31.1 \%)$. The main reasons that the respondents listed for using the VCT service were to know their status, $77.3 \%$, and $17.3 \%$ of requests from health workers. On the other hand, not having a history of sexual intercourse (26\%), fear of a positive test result (10\%), fear of inconsistent health

Table I Socio-Demographic Characteristics of Students in Gondar Teachers Education College $(n=827)$

\begin{tabular}{|l|l|l|l|}
\hline Variables & Categories & Frequency & $\%$ \\
\hline Sex & Male & 396 & 47.9 \\
& Female & 431 & 52.1 \\
\hline Age & $15-19$ & 219 & 26.5 \\
& $20-24$ & 558 & 67.5 \\
& 25 and & 50 & 6.0 \\
\hline Having a boyfriend or & above & & \\
girlfriend & Yes & 420 & 50.8 \\
\hline Years of study & No & 407 & 49.2 \\
\hline Previous residence & Ist year & 225 & 27.2 \\
& 2nd year & 271 & 32.8 \\
& 3rd year & 331 & 40.0 \\
\hline Ethnicity & Rural & 566 & 68.4 \\
& Urban & 261 & 31.6 \\
\hline Had sexual intercourse & Amhara & 692 & 83.7 \\
& Qimant & 135 & 16.3 \\
\hline With whom you live & No & 292 & 35.4 \\
& Family & 237 & 64.7 \\
\hline & Friend & 367 & 28.7 \\
& Alone & 223 & 26.9 \\
\hline
\end{tabular}

care services $(7.9 \%)$, and confidence in their health $(7.1 \%)$ were reasons not to use VCT.

\section{Knowledge and Awareness Towards VCT Among Students}

Overall, 373 (45.1\%) had a comprehensive knowledge of HIV/AIDS, while 130 (41.5\%) of HIV-tested respondents had a comprehensive knowledge of HIV/AIDS. A total of $736(89 \%)$ of respondents heard about HIV. Based on the primary mode of transmission of HIV, 554 (67\%) respondents perceived sexual intercourse, 403 (48.7\%) sharing sharp materials, and 273 (33\%) mother to child during pregnancy as the main means of HIV transmission. Health workers have been described as the main source of information, followed by mass media. About $89 \%$ of respondents were likely to take the HIV test in the future, whether or not they had it in the past. About the understanding of HIV diagnosis, 58\% of respondents thought that VCT knowledge was focused on self-interest. About $71 \%$ of the respondents have heard about VCT. Among the study participants, 367 (77.8\%) had accessed information from the health worker and $63(13.3 \%)$ from the media. More than half $(56.8 \%)$ of participants felt that VCT is successful in preventing the spread of HIV. Over, 207 $(72.6 \%)$ had sex with more than one partner among those who had sexual intercourse. Of the 313 respondents who reported using VCT over the past 12 months, 241 (77\%) suggested that the test site was appealing and that $133(42.5 \%)$ privacy, $114(36.4 \%)$ free service, and $63(20.1 \%)$ positive therapy attitudes were justified.

\section{Factors Associated with VCT Utilization}

Based on multivariable binary logistic regression, being married, peer groups, having boy/girlfriends, knowing individuals infected or died from AIDS, fear of confidentiality of tests, know testing sites, and information about VCT were significantly associated. VCT utilization rates among married students were $64 \%$ less likely than singles $(\mathrm{AOR}=0.36$, 95\% CI: $0.20-0.63)$. The VCT utilization rate among those who had peer groups who used VCT and encouraged them to use it was two times higher than those who did not have (AOR=2.04, 95\% CI: 1.31-3.20).

The chances of using the VCT among students who had partners were 1.6 times higher than their counterparts $(\mathrm{AOR}=1.6,95 \% \mathrm{CI}: 1.04-2.45)$. The chances of using VCT among students who wanted to have VCT in the future were 3.58 times higher than those who did not 
have a plan $(\mathrm{AOR}=3.58,95 \% \mathrm{CI}: 1.98-6.50)$. The chances of VCT utilization among students who knew HIVinfected individuals or dead individuals from AIDS were 1.67 times higher than their counterparts $(\mathrm{AOR}=1.67,95 \%$ CI: 1.07-2.61). VCT utilization rates among students who feared confidentiality were $77 \%$ lower than those of students who did not (AOR=0.23, 95\% CI: $0.10-0.52$ ).

The chances of VCT utilization among students who knew the test sites were 2.01 times higher than those who did not know it (AOR=2.01, 95\% CI: 1.29-3.13). The chances of VCT utilization among knowledgeable students regarding VCT were 1.98 times higher than those with poor knowledge (AOR=1.98, 95\% CI: 1.20-3.34) (Table 2).

\section{Discussion}

This study found that the use of VCTs in college students was low compared to similar areas, although studies have shown that knowing one's serostatus helps prevent and control the spread of HIV/AIDS infection. ${ }^{21,22}$ This finding is consistent with studies conducted in Ethiopia. ${ }^{23-25}$ However, this result is lower than that of another study done in Ethiopia. ${ }^{26}$ The possible explanation for this low

Table 2 Factors Associated with VCT Uptake of Gondar Teachers Education College

\begin{tabular}{|c|c|c|c|c|c|}
\hline \multirow[t]{2}{*}{ Variables } & \multirow[t]{2}{*}{ Categories } & \multicolumn{2}{|c|}{ VCT Utilization } & \multirow[t]{2}{*}{ COR $(95 \%$ C.I) } & \multirow[t]{2}{*}{ AOR (95\% C.I) } \\
\hline & & Yes & No & & \\
\hline Marital status & $\begin{array}{l}\text { Married } \\
\text { Not married }\end{array}$ & $\begin{array}{l}42(29.6 \%) \\
27 I(39.6 \%)\end{array}$ & $\begin{array}{l}100(70.4 \%) \\
414(60.4 \%)\end{array}$ & $\begin{array}{l}0.64(0.43-0.95) \\
1\end{array}$ & $\begin{array}{l}0.36(0.20-0.63)^{*} \\
\mathrm{I}\end{array}$ \\
\hline Residence & $\begin{array}{l}\text { Urban } \\
\text { Rural }\end{array}$ & $\begin{array}{l}108(41.4 \%) \\
205(36.2 \%)\end{array}$ & $\begin{array}{l}153(58.6 \%) \\
36 \mid(63.8 \%)\end{array}$ & $\begin{array}{l}1.243(0.92-1.68) \\
1\end{array}$ & $\begin{array}{l}\text { I.22(0.79-I.88) } \\
\mid\end{array}$ \\
\hline Years of study & $\begin{array}{l}\text { Ist year } \\
\text { 2nd year } \\
3 \text { rd year }\end{array}$ & $\begin{array}{l}70(31.1 \%) \\
116(42.8 \%) \\
127(38.4 \%)\end{array}$ & $\begin{array}{l}155(68.9 \%) \\
155(57.2 \%) \\
204(61.6 \%)\end{array}$ & $\begin{array}{l}\text { I } \\
1.65(1.14-2.40) \\
1.40(0.96-1.97)\end{array}$ & $\begin{array}{l}\text { I } \\
\text { I.66(0.97-2.84) } \\
\text { I.52(0.92-2.5I) }\end{array}$ \\
\hline $\begin{array}{l}\text { Having peer-groups who utilized VCT and encouraged } \\
\text { them to utilize it }\end{array}$ & $\begin{array}{l}\text { Yes } \\
\text { No }\end{array}$ & $\begin{array}{l}139(47.8 \%) \\
174(30.5 \%)\end{array}$ & $\begin{array}{l}117(45.7 \%) \\
397(69.5 \%)\end{array}$ & $\begin{array}{l}2.69(1.97-3.67) \\
1\end{array}$ & $\begin{array}{l}2.04(I .3 \mid-3.20)^{*} \\
I\end{array}$ \\
\hline Had boy/girl friend & $\begin{array}{l}\text { Yes } \\
\text { No }\end{array}$ & $\begin{array}{l}202(48.1 \%) \\
I I I(27.3 \%)\end{array}$ & $\begin{array}{l}218(51.9 \%) \\
296(72.7 \%)\end{array}$ & $\begin{array}{l}2.47(1.85-3.30) \\
1\end{array}$ & $\begin{array}{l}1.60(1.04-2.45)^{*} \\
\mathrm{I}\end{array}$ \\
\hline Who had a desire to have VCT in the future & $\begin{array}{l}\text { Yes } \\
\text { No }\end{array}$ & $\begin{array}{l}302(41 \%) \\
I I(I 2.1 \%)\end{array}$ & $\begin{array}{l}434(59 \%) \\
80(87.9 \%)\end{array}$ & $\begin{array}{l}5.06(2.65-9.67) \\
1\end{array}$ & $\begin{array}{l}3.58(1.98-6.50)^{*} \\
1\end{array}$ \\
\hline $\begin{array}{l}\text { Knowing infected individual with HIV or one who had } \\
\text { died of AIDS }\end{array}$ & $\begin{array}{l}\text { Yes } \\
\text { No }\end{array}$ & $\begin{array}{l}214(46.4 \%) \\
99(27 \%)\end{array}$ & $\begin{array}{l}247(53.6) \\
267(73 \%)\end{array}$ & $\begin{array}{l}2.34(1.75-3.14) \\
I\end{array}$ & $\begin{array}{l}1.67(1.07-2.61)^{*} \\
1\end{array}$ \\
\hline Fear of Confidentiality of test result & $\begin{array}{l}\text { Yes } \\
\text { No }\end{array}$ & $\begin{array}{l}13(21 \%) \\
300(39.2 \%)\end{array}$ & $\begin{array}{l}49(79 \%) \\
465(60.8 \%)\end{array}$ & $\begin{array}{l}0.4 I(0.22-0.77) \\
I\end{array}$ & $\begin{array}{l}0.23(0.10-0.52)^{*} \\
\mathrm{I}\end{array}$ \\
\hline Know testing sites in Gondar & $\begin{array}{l}\text { Yes } \\
\text { No }\end{array}$ & $\begin{array}{l}221(46.8 \%) \\
92(25.9 \%)\end{array}$ & $\begin{array}{l}25 I(53.2 \%) \\
263(74.1 \%)\end{array}$ & $\begin{array}{l}2.52(1.87-3.40) \\
1\end{array}$ & $\begin{array}{l}2.01(1.29-3.13)^{*} \\
1\end{array}$ \\
\hline VCT service encourage youths & $\begin{array}{l}\text { Yes } \\
\text { No }\end{array}$ & $\begin{array}{l}24 I(48.1 \%) \\
50(20.7 \%)\end{array}$ & $\begin{array}{l}260(51.9 \%) \\
192(79.3 \%)\end{array}$ & $\begin{array}{l}3.56(2.49-5.10) \\
1\end{array}$ & $\begin{array}{l}1.65(0.98-2.78) \\
I\end{array}$ \\
\hline Knowledge about HIV & $\begin{array}{l}\text { Good } \\
\text { Poor }\end{array}$ & $\begin{array}{l}\text { I58(42.4\%) } \\
155(34.1 \%)\end{array}$ & $\begin{array}{l}215(57.6 \%) \\
299(65.9 \%)\end{array}$ & $\begin{array}{l}1.42(1.07-1.88) \\
1\end{array}$ & $\begin{array}{l}1.58(0.93-2.68) \\
1\end{array}$ \\
\hline Having awareness about VCT & $\begin{array}{l}\text { Yes } \\
\text { No }\end{array}$ & $\begin{array}{l}235(48.7 \%) \\
26(25 \%)\end{array}$ & $\begin{array}{l}248(51.3 \%) \\
78(75 \%)\end{array}$ & $\begin{array}{l}2.84(1.76-4.60) \\
1\end{array}$ & $\begin{array}{l}1.98(1.20-3.34)^{*} \\
\mathrm{I}\end{array}$ \\
\hline Think positives got adequate support & $\begin{array}{l}\text { Yes } \\
\text { No }\end{array}$ & $\begin{array}{l}220(45 \%) \\
57(25.7 \%)\end{array}$ & $\begin{array}{l}269(55 \%) \\
165(74.3)\end{array}$ & $\begin{array}{l}2.37(1.67-3.56) \\
\text { । }\end{array}$ & $\begin{array}{l}1.13(0.66-1.94) \\
1\end{array}$ \\
\hline
\end{tabular}

Notes: *Statistically significant using the multivariate logistic regression analysis.

Abbreviations: COR, crude odds ratio; AOR, adjusted odds ratio. 
use of VCT could be that the activities performed for the HIV test have been reduced. The findings of this study showed that several socio-demographic, behavioral, and health service-related factors have been associated with the use of HIV VCT among young people.

Those who were not currently married were more likely to use HIV VCT, which is consistent with other studies. ${ }^{9,23}$ A possible reason for this result is, married is believed that they are not infected because of a partner's trust and limited to one sexual partner. This is common among married young people and those with good, comprehensive knowledge of HIV/AIDS have been encouraging partners in some way. ${ }^{8,9,11,23}$ Our findings are consistent with studies conducted in Ethiopia.

Similarly, the use of VCT among students who had fiancé was higher than their counterparts. This finding is in agreement with studies done in Ethiopia. ${ }^{9,24}$ Those who had a boy or a girlfriend could have a better chance of having a VCT as a prerequisite for starting sex. Also, their health outcomes could be discussed and this could have increased health-seeking behavior, including HIV testing and counseling.

Related to the effects of peer pressure, those who had peer groups who used VCT were more likely to use VCT than those who did not. This finding is supported by a study that shows peer support and advice to go to health facilities for VCT services. ${ }^{9}$ In this study, a potential predictor of VCT utilization has been reported as having a desire to have VCT in the future. This finding is consistent with a study in Uganda. ${ }^{10}$ This could be attributed to the fact that a positive attitude is a major factor in the use of VCTs.

The results showed a significant difference in the use of VCTs among students with HIV/AIDS infection/death compared to their counterparts. This finding is consistent with studies in Ethiopia., ${ }^{9,23,26}$ This may have increased their knowledge of the burden of HIV/AIDS and the advantage of early detection of the disease compared to those who did not know the HIV-infected person.

The other findings of the current study showed that there was a significant association between the use of VCT and the presence of confidential testing. This finding is similar to the study conducted in Ethiopia. ${ }^{27}$ The possible reason for this could be because HIV remains a stigmatizing condition, that people feel more comfortable taking the VCT service when they are confident that the issue is kept secret.
The only factor affecting the use of VCT among young people was the programmatic factors affecting the availability of VCT. Besides, this study showed that utilization was dependent on knowledge of VCT availability. This finding is in line with the study in Ethiopia and Uganda. ${ }^{4,21,28,29}$ This is attributed to the fact that more knowledgeable VCT centers will accept offerings and HIV testing and counseling services, which will lead to increased use.

Selection biases, such as non-participation by absence during the survey, may have affected our findings and estimates. Also, there may be a bias in social desirability, as HIV testing is a sensitive issue. Taking all these limitations into account, we still believe that their effect is minimal and unimportant in the explanation of our findings. These findings may, therefore, help programmers and health care providers to design interventions in particular areas of HIV/AIDS for better health outcomes.

\section{Conclusion}

This study found that poor use of VCT services could be a signal to Ethiopia as she is facing a major challenge in achieving the WHO 90:90:90 targets. The main factors identified for increased use of VCT services were marriage, having peer groups that used VCTs and encouraging them to use VCTs, having boys/girlfriends who wanted VCTs in the future, knowledge of infected/dead individuals with HIV/AIDS, fear of confidentiality of results, and knowledge of test sites.

Change is needed to provide effective HIV care and prevention interventions to young people, and thus maximize the benefits of universal test and treat. More emphasis is needed on raising awareness of HIV testing services among adolescents to improve the use of reproductive and sexual health services. Correspondingly, efforts are needed to strengthen the involvement of peer group educators in the management and monitoring of reproductive and sexual health.

\section{Abbreviations}

AOR, adjusted odds ratio; COR, crude odds ratio; ART, antiretroviral therapy; AIDS, acquired immunodeficiency syndrome; HIV, human immunodeficiency virus; VCT, voluntary counseling and testing; WHO, World Health Organization.

\section{Data Sharing Statement}

All relevant data are within the paper. However, data are available from the corresponding author upon reasonable request. 


\section{Ethics Approval and Consent to Participate}

The study was conducted in accordance with the Declaration of Helsinki and approved by the University of Gondar Ethical Review Board. Ethical clearance was obtained from the ethics review committee of the University of Gondar with the reference number of $\mathrm{V} / \mathrm{P} / \mathrm{R} /$ $\mathrm{CS} / 05 / 1153 / 2018$. The high-level officials of Gondar teachers' education college wrote a permission letter to conduct this study. Verbal and written informed consent was taken from each study participants who were aged $\geq 18$ years after being carefully explained in their local language for the study. Assent was obtained for those who were aged $\geq 15$ years after explaining the purpose of the study, in addition to the consent of the parent or guardian/higher officials of Gondar teachers' education college.

\section{Consent for Publication}

Not applicable.

\section{Acknowledgments}

We would like to acknowledge the University of Gondar for technical support to conduct this research. We would also like to thank the Central Gondar Zone Health Department and the Gondar Teachers' Education College Authorities for their permission. Our sincere appreciation goes also to supervisors, data collectors, and study participants.

\section{Author Contributions}

All authors contributed to data analysis, drafting or revising the article, have agreed on the journal to which the article will be submitted, gave final approval of the version to be published, and agree to be accountable for all aspects of the work.

\section{Funding}

This study did not receive any funding from any organization.

\section{Disclosure}

The authors declare that they do not have competing interests.

\section{References}

1. WHO. HIV/AIDS. Available from: https://www.who.int/news-room /fact-sheets/detail/hiv-aids. Accessed January 17, 2019.
2. EPHI. HIV Related Estimates and Projections for Ethiopia. 2017.

3. Standard A. HIV/AIDS is surging in Ethiopia, again. Addis Standard, October 2017.

4. UNICEF. Adolescents and young people health; 2016. Available from: https://datauniceforg/topic/hivaids/adolescents-young-people/.

5. Joseph A, Patrick N, Lawrence N, Lilian O, Olufemi A. Evaluation of Malaria surveillance system in Ebonyi state, Nigeria. Ann Med Health Sci Res. 2014;7(Special Issue 1).

6. UNAIDS. UNAIDS 2017 estimates. 2017.

7. UNAIDS. Global aids update: Geneva, Switzerland. 2016.

8. MOH/HAPCO A, CSA, and EPHA. HIV/AIDS Behavioral Surveillance Survey (BSS) Ethiopia 2005 Round Two, Addis Ababa, Ethiopia. 2005.

9. Endris T. Assessment of HIV voluntary counseling and testing service utilization and associated factors among Gambella Teachers' Education and Health Science College Students in Gambella Regional State, South West Ethiopia. 2017.

10. UNICEF. Analysis of UNAIDS data. 2016.

11. Federal Democratic Republic Of Ethiopia. Demographic And Health Survey, Key Indicators Report. 2016.

12. Ga M Annual report. 2017.

13. Vermeer WBEMJ, Kaaya S, Schaalma PH, Kaaya S, Schaalma HP. Social and cognitive variables predicting voluntary HIV counseling and testing among Tanzanian medical students. Patient Educ Couns. 2009;75:135-140. doi:10.1016/j.pec.2008.08.022

14. UNAIDS. The impact of Voluntary Counseling and Testing: a global review of the benefits and challenges joint United Nations program on HIV/AIDS. 2001.

15. Tsegaye GEM, Meseret N. Assessment of voluntary counseling and testing service utilization and associated factors among Debre Markos University Students, North West Ethiopia: a cross-sectional survey. BMC Health Serv Res. 2011;13:243.

16. Ko A. HIV/AIDS knowledge and uptake of HIV counseling and testing among undergraduate private university students in Accra, Ghana. Reprod Health. 2013;10:17. doi:10.1186/17424755-10-17

17. 2016 CSACaI. Ethiopia demographic and health survey. Addis Ababa, Ethiopia 2016; 2016. Available from. https://dhsprogram com/pubs/pdf/PR81/PR81pdf.

18. UNAIDS. Fact sheet of HIV/AIDS. 2018.

19. Addis ZYA, Shiferaw Y, Alemu A, et al. Knowledge, attitude and practice towards voluntary counseling and testing among university students in North West Ethiopia. BMC Public Health. 2013;13:714. doi:10.1186/1471-2458-13-714

20. Mitike MYB, Bernt L. Perception of Ethiopian youth regarding their risk of HIV: a community-based study among youth in predominately rural Butajira. Ethiopia. J Rep Health. 2009;3:44-51.

21. Bunnell R, Solberg P, Solberg P, et al. Changes in sexual behavior and risk of HIV transmission after antiretroviral therapy and prevention interventions in rural Uganda. AIDS. 2006;20(1):85-92. doi:10.1097/01.aids.0000196566.40702.28

22. Arthur G, Forsythe S, Mutemi R, Odhiambo J, Gilks C, Gilks C. Behaviour change in clients of health centre-based voluntary HIV counselling and testing services in Kenya. Sex Transm Infect. 2007;83(7):541-546. doi:10.1136/sti.2007.026732

23. Getachew Fikadie MB, Alamrew Z. Prevalence of Voluntary Counseling and Testing $U$ tilization and Its Associated Factors among Bahirdar University Students. 2014.

24. Zeytu G. Knowledge, Attitude Towards Practicing of Voluntary HIV Counseling and Testing and the Determinants of VCT Uptake: A Case Study in Debre Birhan Students Training College. South Africa: Statistics South Africa; 2007.

25. Andarge A. Determinants of voluntary HIV counseling and testing among Addis Ababa university undergraduate final year students [Ph.D. thesis], School of Graduate Studies, Addis Ababa University. 2008. 
26. Selamawit Dagne EA, Misikir D, Haftu D. Voluntary Counseling and Testing Utilization and Associated Factors among Arba Minch University Students, South Ethiopia. 2014.

27. Tesfay G. Assessment of voluntary counseling and testing service utilization and associated factors among Debre Markos University Students, North West Ethiopia: a cross-sectional survey in 2011.
28. Regassa NKS. Attitudes and practices on HIV preventions among students of higher education institutions in Ethiopia: the case of Addis Ababa University. East Afr J Public Health. 2011;2:828-840.

29. Singa ZKG, Musya S, Mwangi R. Factors influencing the uptake of VCT service among secondary school students in Arusha city, Tanzania. J Bio Med Center Public Health. 2014;15:1-9.

\section{Publish your work in this journal}

HIV/AIDS - Research and Palliative Care is an international, peerreviewed open-access journal focusing on advances in research in HIV, its clinical progression and management options including antiviral treatment, palliative care and public healthcare policies to control viral spread. The manuscript management system is completely online and includes a very quick and fair peer-review system, which is all easy to use. Visit http://www.dovepress.com/testimonials.php to read real quotes from published authors. 